\title{
A Cre-Dependent GCaMP3 Reporter Mouse for Neuronal Imaging In Vivo
}

\author{
Hatim A. Zariwala, ${ }^{1,2}$ Bart G. Borghuis, ${ }^{1}$ Tycho M. Hoogland, ${ }^{3}$ Linda Madisen, ${ }^{2}$ Lin Tian, ${ }^{1}$ Chris I. De Zeeuw, ${ }^{3,4}$ \\ Hongkui Zeng, ${ }^{2}$ Loren L. Looger, ${ }^{1}$ Karel Svoboda, ${ }^{1}$ and Tsai-Wen Chen ${ }^{1}$ \\ ${ }^{1}$ Janelia Farm Research Campus, Howard Hughes Medical Institute, Ashburn, Virginia 20147, ${ }^{2}$ Allen Institute for Brain Science, Seattle, Washington 98103 , \\ ${ }^{3}$ Netherlands Institute for Neuroscience, Royal Netherlands Academy of Arts and Sciences (KNAW), 1105 BA Amsterdam, The Netherlands, and \\ ${ }^{4}$ Department of Neuroscience, Erasmus Medical Center, 3015 GE Rotterdam, The Netherlands
}

Fluorescent calcium indicator proteins, such as GCaMP3, allow imaging of activity in genetically defined neuronal populations. GCaMP3 can be expressed using various gene delivery methods, such as viral infection or electroporation. However, these methods are invasive and provide inhomogeneous and nonstationary expression. Here, we developed a genetic reporter mouse, Ai38, which expresses GCaMP3 in a Cre-dependent manner from the ROSA26 locus, driven by a strong CAG promoter. Crossing Ai38 with appropriate Cre mice produced robust GCaMP3 expression in defined cell populations in the retina, cortex, and cerebellum. In the primary visual cortex, visually evoked GCaMP3 signals showed normal orientation and direction selectivity. GCaMP3 signals were rapid, compared with virally expressed GCaMP3 and synthetic calcium indicators. In the retina, Ai38 allowed imaging spontaneous calcium waves in starburst amacrine cells during development, and light-evoked responses in ganglion cells in adult tissue. Our results show that the Ai38 reporter mouse provides a flexible method for targeted expression of GCaMP3.

\section{Introduction}

A growing tool kit of fluorescent molecules allows the readout of neuronal function, including membrane potential (Grinvald and Hildesheim, 2004), intracellular [ $\mathrm{Ca}^{2+}$ ] (Tsien, 1989; Mank and Griesbeck, 2008), and G-protein (Yasuda et al., 2006) and kinase activation (Miyawaki, 2005; Harvey et al., 2008). State-of-the-art synthetic calcium indicators such as Fura-2 (Grynkiewicz et al., 1985), Oregon Green BAPTA-1 (OGB-1), and Fluo-4 exhibit high signal-to-noise ratios (SNRs). Their AM-ester isoforms (Tsien et al., 1982) can be loaded into many types of tissue (Regehr and Tank, 1991; Yuste et al., 1992; Stosiek et al., 2003). Although bulk-loaded synthetic indicators have been used widely (Kerr et al., 2005; Ohki et al., 2005; Dombeck et al., 2007; Sato et al., 2007; Chen et al., 2009; Andermann et al., 2010; Komiyama et

\footnotetext{
Received Aug. 31, 2011; revised Dec. 17, 2011; accepted Jan. 9, 2012.

Author contributions: H.Z., K.S., and T.-W.C. designed research; H.A.Z., B.G.B., T.M.H., and T.-W.C. performed research; L.M., L.T., C.I.D.Z., H.Z., L.L.L., and T.-W.C. contributed unpublished reagents/analytic tools; B.G.B., T.M.H., and T.-W.C. analyzed data; H.A.Z., B.G.B., T.M.H., H.Z., L.L.L., K.S., and T.-W.C. wrote the paper.

This work was supported by the Howard Hughes Medical Institute and the Allen Institute for Brain Science, and by an NIH grant (DA028298) to H.Z. We thank M. Stryker and C. Niell for advice in visual cortex imaging, L. Petreanu for suggestions with the experimental design, S. Wang and D. Kim for comments on this manuscript, K. Smith and A. Hu for surgical and histological support, D. Flickinger for help with microscope design, Q. Sun and E. Schreiter for help with measuring intracellular GCaMP3 concentration, and S. Sternson for providing Cre virus.

The authors declare no competing financial interests.

This article is freely available online through the $J$ Neurosci Open Choice option.

Correspondence should be addressed to either of the following: Hongkui Zeng at the above address, E-mail: hongkuiz@alleninstitute.org; or Tsai-Wen Chen at the above address, E-mail: chent@janelia.hhmi.org.

H. A. Zariwala's present address: Center for Integrative Brain Research, Seattle Children's Research Institute, Seattle, WA 98101.

B. G. Borghuis's present address: Department of Ophthalmology and Visual Science, Yale University, New Haven, CT 06510 .

DOI:10.1523/JNEUROSCI.4469-11.2012

Copyright $\odot 2012$ the authors $\quad 0270-6474 / 12 / 323131-11 \$ 15.00 / 0$
}

al., 2010) for functional imaging in neurons, they have significant drawbacks. Labeling is indiscriminate, invasive, and has a short half-life. Repeated imaging is rarely done.

Genetically encoded calcium indicators (GECIs) are beginning to overcome these obstacles (Nakai et al., 2001; Nagai et al., 2004; Palmer et al., 2006; Mank and Griesbeck, 2008). GECIs allow long-term imaging with reasonable SNR (Mank et al., 2008; Tian et al., 2009). GECIs can be targeted to defined cell populations and subcellular compartments (Miyawaki et al., 1997; Mao et al., 2011). Recent protein engineering has provided improved single-wavelength [e.g., GCaMP3 (Tian et al., 2009); GCaMP-HS (Muto et al., 2011)] and ratiometric [e.g., TN-XXL (Mank et al., 2008); D3cpV (Palmer et al., 2006); YC3.60 (Nagai et al., 2004)] indicators that have been deployed in many model organisms.

GECIs have to be introduced using gene transfer methods. Mouse experiments have mostly relied on in utero electroporation (IUE) (Mank et al., 2008; Mao et al., 2008) or viral infection (Tian et al., 2009; Lütcke et al., 2010; Borghuis et al., 2011). These methods require surgery on each animal, produce inhomogeneous expression patterns, and lead to undesirable expression timelines. For example, IUE produces high expression early during development, which can cause permanent cytotoxicity (Tian et al., 2009). Viral transduction ramps up over time, causing nonstationary expression levels. Transgenic methods of expression could potentially solve these issues.

Several GECI-expressing transgenic mouse lines have been reported (Hasan et al., 2004; Díez-García et al., 2005; Tallini et al., 2006, 2007; Heim et al., 2007; Atkin et al., 2009), but each of these transgenic mouse lines produced robust expression only in selected tissues, limiting their utility. Among GECIs, the recently developed indicator GCaMP3 has superior sensitivity, SNR, and 
photostability (Tian et al., 2009). Here, we report a GCaMP3 reporter mouse (Ai38) based on the flexible Cre/lox system (Sauer and Henderson, 1988; Orban et al., 1992). Upon crossing with different Cre lines, Ai38 reporter mice allow flexible and reproducible GCaMP3 expression in a wide variety of neuronal classes, including ganglion and starburst amacrine cells in the retina, pyramidal cells in the cortex, and Purkinje cells in the cerebellum. We validate the performance of GCaMP3 in these neuronal populations under physiological conditions.

\section{Materials and Methods}

All surgeries and experimental procedures were conducted under guidelines of the Janelia Farm Research Campus Institutional Animal Care and Use and Biosafety Committees. Adult mice (P56-P120) of either sex were used in most experiments, unless otherwise noted.

Transgenic mice. The Ai38 floxed GCaMP3 reporter mouse line was generated using a knock-in strategy into the ROSA26 locus that was previously demonstrated to have robust and ubiquitous expression of the transgene by using the CAG (cytomegalovirus early enhancer/chicken $\beta$-actin) promoter and the woodchuck hepatitis virus posttranscriptional regulatory element (WPRE), made Cre-dependent with a loxstop-lox (LSL) cassette (Madisen et al., 2010). The GCaMP3 insert was cloned into a ROSA26-pCAG-LSL-WPRE-bGHpA targeting vector (Madisen et al., 2010), in between the LSL and the WPRE sequences. The LSL sequence contained LoxP-Stop codons $-3 \times$ SV40 poly(A)-LoxP. The final targeting vector (Fig. $1 \mathrm{~A}$ ) also contained $5^{\prime}$ and $3^{\prime}$ homology arms of 1.1 and $4.3 \mathrm{~kb}$, as well as an AttB-pPGK-FRT-Neo-PGK poly(A)AttP cassette for positive selection, but it did not contain a PPGK-DTA cassette for negative selection. The targeting vector was linearized and transfected into the 129/B6 F1 hybrid embryonic stem (ES) cell line, G4. G418 (Geneticin)-resistant (thus containing the neomycin resistance marker aminoglycoside 3'-phosphotransferase, Neo) ES clones were screened by PCR using primers spanning the $1.1 \mathrm{~kb} 5^{\prime}$ genomic arm (forward primer, 5'-gggctccggctcctcagaga-3'; reverse primer, $5^{\prime}$-atgccaggcgggccatttac- $\left.3^{\prime}\right)$.

Correctly targeted ES clones were injected into C57BL/6J blastocysts to obtain chimeric mice following standard procedures. Chimeric mice were bred with $\mathrm{C} 57 \mathrm{BL} / 6 \mathrm{~J}$ mice to obtain germline transmitted $\mathrm{F} 1$ mice. Progeny mice from a single correctly targeted ES clone were maintained and used for studies. Southern blot analysis (see Fig. $1 A$ ) was performed on these mice to confirm the correct targeting into the ROSA26 locus by probing HindIII-digested genomic DNA with a $1.1 \mathrm{~kb}$ genomic fragment from immediately upstream of the $5^{\prime}$ arm, as well as to confirm the single-copy integration of the transgene by probing SulI/SapI- or StuI/ BclI-digested genomic DNA with an 798 bp SalI/MluI fragment from GCaMP3. Genotyping of the Ai38 mice was performed by PCR (forward primer, $5^{\prime}$-cttcaagatccgccacaacatcg- $3^{\prime}$; reverse primer, $5^{\prime}$-ttgaagaagatggtgcgctcctg- $3^{\prime}$ ), which amplifies a 546 bp fragment of GCaMP3.

The Ai38 mice used in the current studies still contain the PGK-Neo marker cassette downstream of the GCaMP3 expression cassette. If desired, the PGK-Neo cassette can be deleted by breeding the Ai38 mice with ROSA26-PhiC31 mice (JAX stock no. 007743). Our previous experience did not indicate any expression difference between the Ai-series of reporter lines with or without the PGK-Neo cassette (e.g., between Ai9 and Ail4 floxed tdTomato reporters) (Madisen et al., 2010).

Cre driver mouse lines were crossed with the Ai38 reporter mouse (see Fig. 1). The $W f_{s} 1-T g 2-C r e E R T 2$ is a BAC transgenic line (JAX no. 009614) with inducible CreERT2 (Feil et al., 1997) recombinase expression restricted to $\mathrm{Wfs}_{\mathrm{s}} \mathrm{s}^{+}$(Wolfram syndrome 1) excitatory neurons. Cre activation requires tamoxifen administration in postnatal mice through oral gavage, at a dose of $200 \mu \mathrm{g} / \mathrm{g}$ body weight per day for $5 \mathrm{~d}$ (Madisen et al., 2010). The Pvalb-2A-Cre (JAX no. 012358), Emxl-Cre (JAX no. 005628), Pcp2-Cre (JAX no. 004146), and Chat-Cre (JAX no. 006410) lines have Cre knocked into Pvalb (parvalbumin) (Madisen et al., 2010), Emx1 (homeobox protein) (Gorski et al., 2002), Pcp2 (Purkinje cell protein 2) (Barski et al., 2000), and Chat (choline acetyltransferase) (Ivanova et al., 2010), respectively. All Cre lines produced faithful expression patterns compared with their cognate genes.
Mouse and DNA availability. We have deposited the Ai38 mice to The Jackson Laboratory for distribution (JAX stock no. 014538; http://jaxmice.jax.org/strain/014538.html). We have also deposited the Ai38 targeting vector DNA plasmid to Addgene (http://www.addgene.org/).

Viral infection. Adenoassociated virus AAV2/1 carrying the construct synGCaMP3 (GCaMP3 under the neural-specific human synapsin-1 promoter) (Kügler et al., 2001) $\left(2.25 \times 10^{13}\right.$ genome copies/ $\mu$ l) was injected at a depth of $\sim 250 \mu \mathrm{m}$ to the primary visual cortex (two sites, 2.5 and $2.9 \mathrm{~mm}$ lateral from the lambda suture) of adult ( $\sim 2$ months) C57BL/6J mice. Small volumes ( $\sim 30 \mathrm{nl}$ ) of viral suspension were delivered over a period of $5 \mathrm{~min}$ per site using a custom-built volumetric injector. The AAV was allowed to infect and express GCaMP3 for 3 weeks after injection.

Mouse preparation for in vivo imaging. Mice were anesthetized using isoflurane (3\% for induction, $1.5-2 \%$ during surgery). In some cases, 2 $\mathrm{mg} / \mathrm{kg}$ dexamethasone was administered intraperitoneally to reduce brain edema. A circular craniotomy $(2-3 \mathrm{~mm}$ diameter) was placed above V1 (centered $2.7 \mathrm{~mm}$ lateral from lambda suture). OGB-1-AM (Invitrogen) was injected as previously described (Stosiek et al., 2003; Komiyama et al., 2010; Zariwala et al., 2011). The craniotomy was covered with agarose $(1.2-1.5 \%)$ and a round glass coverslip (Warner Instruments; $5 \mathrm{~mm}$ diameter; no. 1 thickness) was cemented to the skull to reduce motion of the exposed brain. A custom titanium head post was fixed to the skull using black dental cement (Contemporary Ortho-Jet). The animal was then transferred to the imaging setup, where it was placed on a warm blanket $\left(37^{\circ} \mathrm{C}\right)$ and kept anesthetized using $0.5 \%$ isoflurane and sedated with chlorprothixene $(20-40 \mu \mathrm{l}$ at $0.33 \mathrm{mg} / \mathrm{ml}, \mathrm{i} . \mathrm{m}$.) (Niell and Stryker, 2008).

In vivo imaging. Imaging was done with a custom-built two-photon microscope (designs available at http://research.janelia.org/Svoboda/). The light source was a Mai-Tai 80 fs pulsed laser (Spectra Physics) running at 900 $\mathrm{nm}$ for GCaMP3 and $800 \mathrm{~nm}$ for OGB-1. The objective was a $40 \times$ dipping lens (Olympus; $40 \times, 0.8 \mathrm{NA}$ ). Image acquisition was performed using ScanImage 3.7 (www.scanimage.org) (Pologruto et al., 2003). Images $(512 \times 256$ pixels; $250 \times 250 \mu \mathrm{m}$ ) were collected at $4 \mathrm{~Hz}$ for V1 experiments. For cerebellum experiments, images were acquired at 8 or $16 \mathrm{~Hz}$.

Visual stimuli. The moving grating stimuli were generated using the Psychophysics Toolbox (Brainard, 1997; Pelli, 1997) in MATLAB (MathWorks). Each stimulus trial consisted of a $4 \mathrm{~s}$ blank period (uniform gray at mean luminance) followed by a $4 \mathrm{~s}$ drifting sinusoidal grating $(0.05$ cycles per degree; $1 \mathrm{~Hz}$ temporal frequency). The visual stimuli were synchronized to individual image frames using frame-start pulses provided by ScanImage 3.7. The gratings were presented through an LCD monitor $(30 \times 40 \mathrm{~cm})$, placed $25 \mathrm{~cm}$ in front of the center of the right eye of the mouse. The monitor subtended an angle of $\pm 38^{\circ}$ horizontally and -20 to $+38^{\circ}$ vertically around the eye of the mouse.

Data analysis. Slow drifts in brain position in the $\mathrm{X}$ and $\mathrm{Y}$ directions were corrected using the Turboreg plug-in in ImageJ (Thévenaz et al., 1998). All remaining analyses were performed in MATLAB. Regions of interest (ROIs) corresponding to visually identifiable cell bodies were selected using a semiautomated algorithm. For GCaMP3, ring-shaped ROIs were placed at the cytosolic regions of the cells [excluding the nucleus; GCaMP3 expression is typically restricted to the cytoplasm (Tian et al., 2009)]. For OGB-1, circular ROIs covering the whole soma were used. The fluorescence time course of each cell was measured by averaging all pixels within the ROI. The neuropil contamination was corrected using published methods (Kerlin et al., 2010); in short, the neuropil signal $F_{\text {neuropil }}(t)$ surrounding each cell was measured by averaging the signal of all pixels within a $20 \mu \mathrm{m}$ circular region from the cell center (excluding all selected cell bodies). The true fluorescence signal of a cell body was estimated as follows:

$$
F_{\text {cell_true }}(t)=F_{\text {cell_measured }}(t)-\left(r F_{\text {neuropil }}(t)\right),
$$

with $r=0.3$ throughout the study. After neuropil correction, the $\Delta F / F_{0}$ of each trial was calculated as $\left(F-F_{0}\right) / F_{0}$, where $F_{0}$ is the baseline fluorescence signal averaged over a $2 \mathrm{~s}$ period immediately before the start of grating stimulation. Visually responsive neurons were defined using ANOVA across blank and eight direction periods $(p<0.01)$ (Ohki et al., $2005)$. Of the responsive cells, orientation-selective cells were defined by ANOVA across eight direction periods $(p<0.01)$. 
A
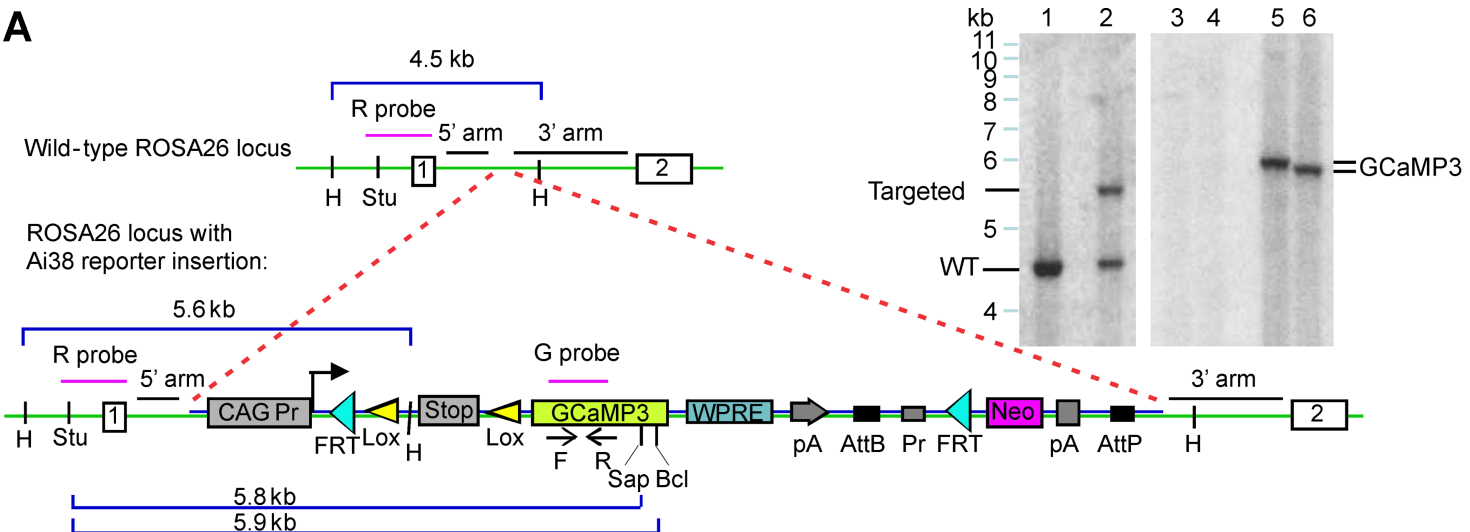
,

B

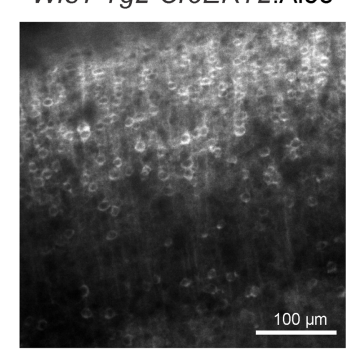

F

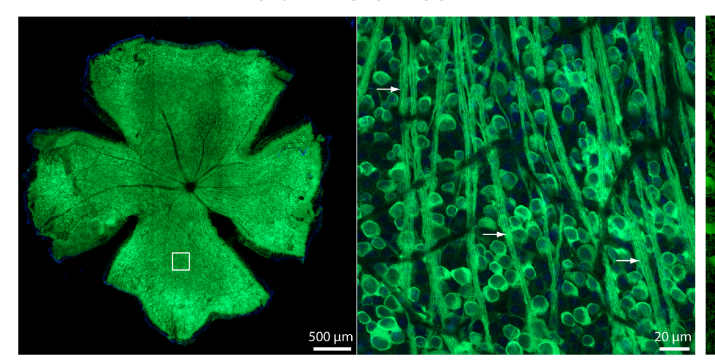

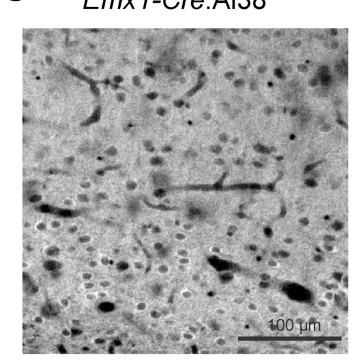

D

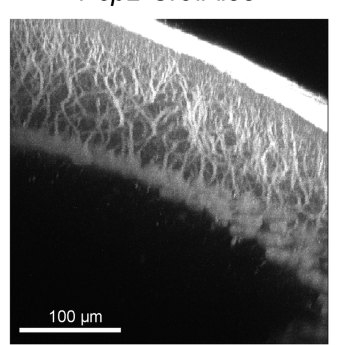

E

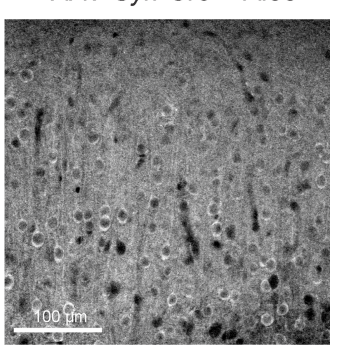

G

Chat-Cre:Ai38

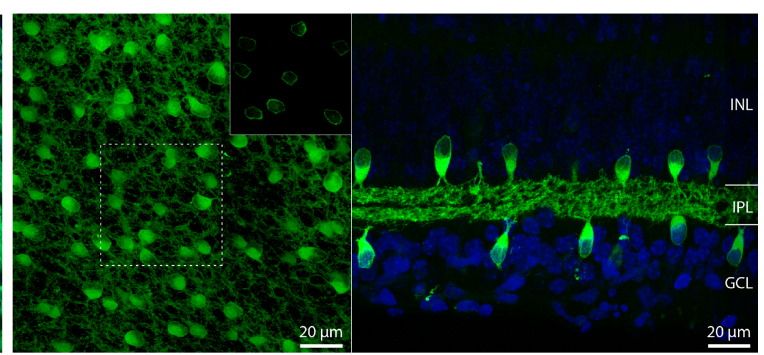

Figure 1. Expression of GCaMP3 in various cell populations in the Ai38 mouse. A, Schematic of the gene targeting strategy to generate the Ai38 reporter mice. GCaMP3-containing Cre reporter cassette (shown in between the dashed red lines) was targeted to the ROSA26 locus in the intron between endogenous exons 1 and 2 . Locations of the $5^{\prime}$ and $3^{\prime}$ arms (1.1 and 4.3 kb, respectively) for homologous recombination are indicated by the black bars. Genotyping primers are located in the GCaMP3 sequence, as indicated by the open arrows (the F and R primers). Correct gene targeting was confirmed by Southern blot (top right, lanes 1-2) using the ROSA26 locus-specific probe (the R probe) immediately upstream of the $5^{\prime}$ arm on HindIII (H)-digested genomic DNA, which gives rise to a $4.5 \mathrm{~kb}$ band for the wild-type (WT) locus and a $5.6 \mathrm{~kb}$ band for the gene-targeted locus. Lane 1, HindIII on WT ES cell DNA. Lane 2, HindllI on Ai38 mouse tail DNA. The single-copy integration of the transgene was confirmed by the appearance of a single band in Southern blot (top right panel, lanes 3-6) using the GCaMP3-specific probe (the G probe) on Stul/BCll- or Stul/Sapl-digested genomic DNA, which gives rise to a $5.9 \mathrm{~kb}$ or a $5.8 \mathrm{~kb}$ band, respectively. Lane 3, Stul/Bcll on WT ES cell DNA. Lane 4, Stul/Sapl on WT ES cell DNA. Lane 5, Stul/Bcll on Ai38 mouse tail DNA. Lane 6, Stul/Sap/ on Ai38 mouse tail DNA. B, Native fluorescence of GCaMP3 in a coronal cortical section from a Wfs1-Tg2-CreERT2:Ai38 mouse. C, GCaMP3 fluorescence in a cortical section of a Emx1-Cre:Ai38 mouse. D, Pcp2-Cre:Ai38 mouse expressing GCaMP3 in cerebellar Purkinje cells, native GCaMP3 fluorescence. $\boldsymbol{E}$, GCaMP3 fluorescence near the AAV-syn-Cre injection site in the cortex of an Ai38 mouse. F, Pvalb-2A-Cre:Ai38 mouse expressing GCaMP3 in retinal ganglion cells. The retina was radially incised to permit flattening on a microscope glass slide for confocal microscopy. Green, GCaMP3; blue, DAPI. Radial blood vessels (black) are visible, converging on the optic disk (center). Right, Z-projection of confocal stack through the fiber and ganglion cell layers (higher magnification of the boxed area). The image shows GCaMP3-expressing ganglion cells and bundles of GCaMP3-positive axons (arrows), oriented toward the optic disk. G, Ai38 crossed with Chat-Cre targets GCaMP3 expression to SACs. Left, Maximum intensity projection of a confocal stack through the ganglion cell layer (GCL), inner plexiform layer (IPL), and inner nuclear layer (INL) of a whole-mount retina (age P8). Inset, Single z-plane through somata of SACS in the INL. Right, Confocal image of a side-on view of the same retinal slice.

The orientation selectivity index (OSI), tuning width, and direction selectivity index (DSI) were calculated for visually responsive cells. First, the preferred orientation $\left(\theta_{\text {pref }}\right)$ of the cell was determined as the angle of the grating that produced the strongest response. The orientation tuning curve was constructed by measuring the mean $\Delta F / F_{0}$ over the $4 \mathrm{~s}$ stimulus period for each orientation. We then fitted the tuning curve as the sum of two Gaussian functions centered on $\theta_{\text {pref }}$ and $\theta_{\text {pref }}+\pi$ with equal width $\sigma$, different amplitudes $A_{1}$ and $A_{2}$, and a constant baseline $\mathrm{B}$ (Niell and Stryker, 2008). The value of $\sigma$ was required to be $>15^{\circ}$ to reflect the limit of our stimulus set $\left(45^{\circ}\right.$ separation) in resolving sharper tuning. The OSI was defined as follows:

$$
\frac{R_{\text {pref }}-R_{\text {ortho }}}{R_{\text {pref }}+R_{\text {ortho }}}
$$

where $R_{\text {pref }}$ and $R_{\text {ortho }}$ are the response amplitudes at the preferred ( $\left.\theta_{\text {pref }}\right)$ and the orthogonal orientation $\left(\theta_{\text {pref }}+\pi / 2\right)$. Tuning width (TW) was defined as the half-width at half-maximum of the fitted Gaussian (TW $=\sigma \cdot \sqrt{2 \cdot \ln 2}$ ). Finally, DSI was calculated as follows:

$$
\frac{R_{\text {pref }}-R_{\text {opposite }}}{R_{\text {pref }}+R_{\text {opposite }}}
$$

where $R_{\text {opposite }}$ is the response in the opposite direction $\left(\theta_{\text {pref }}+\pi\right)$.

Estimation of intracellular GCaMP3 concentration. We measured intracellular GCaMP3 concentrations in acute coronal brain slice of Emx1Cre:Ai38 mice. The cytosolic GCaMP3 fluorescence in multiple individual neurons was measured using a two-photon microscope. The slice was incubated in artificial CSF with $20 \mathrm{~mm}$ extracellular $\left[\mathrm{Ca}^{2+}\right]$ and 
$1 \mathrm{~mm}$ ionomycin to produce saturating intracellular calcium levels. Neuronal brightness was compared with calibrated solutions of GCaMP3 in a thin cuvette.

Histology. Coronal sections $(50 \mu \mathrm{m})$ of the visual cortex were imaged using a confocal microscope (Zeiss LSM 510). Special care was taken to avoid saturation of the image pixels. Identical laser power and image settings were used for the intensity comparisons shown in Figure 2E. The brightness of individual cells was measured by averaging pixels within ROIs covering the cytosolic regions. Background (measured in nearby cell-free regions) was subtracted.

Retinal imaging in vitro. Confocal fluorescence images of GCaMP3 expression patterns in the retina (Fig. $1 F, G$ ) were obtained with a Zeiss LSM 510 laser-scanning microscope. For functional imaging in vitro, retinas were prepared using standard methods (Borghuis et al., 2011). A retina was removed from the sclera and mounted on nitrocellulose filter paper (HAWP01300; Millipore), photoreceptor side down. Apertures ( $1 \mathrm{~mm}$ diameter) in the filter paper permitted light stimulation of the photoreceptors through the condenser lens. Retinas were continuously perfused with oxygenated $(95 \%$ $\mathrm{O}_{2} / 5 \% \mathrm{CO}_{2}$ ) Ames medium (Sigma-Aldrich) at $37^{\circ} \mathrm{C}$.

Two-photon fluorescence measurements were obtained with a modified Olympus BX microscope with an Olympus 60×, 0.9 NA, LUMPlanFl/IR objective, an ultrafast pulsed laser (Chameleon Vision II; Coherent) tuned to $910 \mathrm{~nm}$, and controlled with ScanImage. Images $(512 \times 128$ pixels $)$ were acquired at 16 frames per second. Electrical field stimulation (1 kHz, $20 \mathrm{nA}$ peak current) was generated with the capacitance compensation circuit on a Neurodata intracellular amplifier and delivered through the patch pipette $(\sim 3 \mathrm{M} \Omega)$. All data were analyzed with custom algorithms in MATLAB as described previously (Borghuis et al., 2011).

\section{Results}

The Ai38 line was crossed to Cre lines to express GCaMP3 in selected cell populations in the retina, cerebral cortex, and cerebellum. We labeled retinal ganglion cells by crossing the Ai38 mouse to Pvalb-2A-Cre (Madisen et al., 2010) and Chat-Cre (Ivanova et al., 2010) mice. For imaging primary visual cortex (V1), Ai38 was crossed with three different Cre lines, Wfs1-Tg2CreERT2, Pvalb-2A-Cre, and Emx1-Cre, which label different but overlapping cortical cell populations (Madisen et al., 2010). For imaging Purkinje cells, Ai38 was crossed with Pcp2-Cre mice (Barski et al., 2000). Results from the Ai38 mouse were compared with published data collected with small molecule dyes and virally transduced GECIs. For V1 imaging, we also performed a side-by-side comparison of Ai38-GCaMP3 with OGB-1 and AAV-syn-GCaMP3, under identical experimental conditions.

\section{Characterization of the Ai38 line}

The Ai38 reporter mouse carries the GCaMP3 gene under control of the $C A G$ promoter to drive high levels of transgene expression. Expression was made Cre-dependent by introduction of a lox-stop-lox cassette (Fig. 1A). The construct was
AAV-syn-GCaMP3

4 weeks post injection)
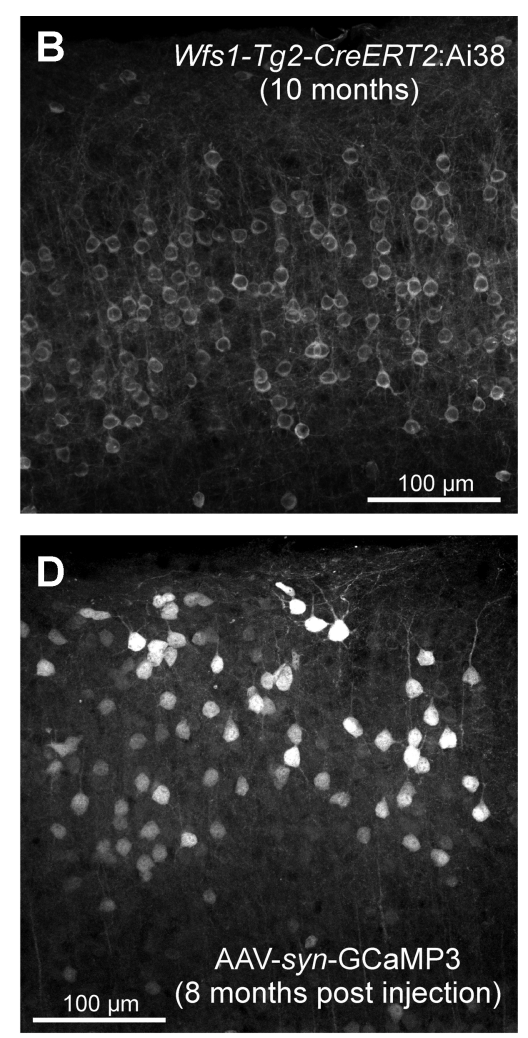

Figure 2. Stable expression levels in the Ai38 mouse over months. Native GCaMP3 fluorescence in layer 2/3 of visual cortex from Wf57-Tg2-CreERT2:Ai38 mice $(\boldsymbol{A}, \boldsymbol{B})$ and adult wild-type mice infected with AAV-syn-GCaMP3 $(\boldsymbol{C}, \boldsymbol{D})$. $\boldsymbol{E}$, Quantification of neuronal brightness. Error bars correspond to SEM.

targeted to the permissive ROSA26 locus (Soriano, 1999). Cell-specific GCaMP3 expression was achieved by crossing the Ai38 reporter mice with $W f_{s} 1-T g 2-C r e E R T 2, E m \times 1-C r e, P c p 2-$ Cre, Pvalb-2A-Cre, and Chat-Cre mice. Expression patterns in the cortex (Fig. $1 B, C$ ), cerebellum (Fig. $1 D$ ), and the retina (Fig. $1 F, G$ ) are consistent with the Cre expression patterns of the driver lines (Barski et al., 2000; Gorski et al., 2002; Ivanova et al., 2010; Madisen et al., 2010). GCaMP3 expression in the Ai38 mouse was also confirmed with Cre delivery through AAV infection in the cortex. This led to homogeneous GCaMP3 expression in cells around the injection site (Fig. $1 E$ ).

Previous GECI delivery using IUE or viral infection produced a subpopulation of cells (typically at the site of injection) with strong nuclear fluorescence (Tian et al., 2009). These filled cells displayed abnormal physiology and attenuated stimulus-evoked responses (Tian et al., 2009). Furthermore, the number of filled neurons increased with time, which fundamentally limits the duration and stability of chronic GECI imaging. We examined GCaMP3 fluorescence in various Ai38 crosses in brain areas including the cortex (Figs. $1 B, C, 2 A$ ), retina (Fig. $1 F, G$ ), and cerebellum (Fig. $1 D$ ). In all cases, we detected virtually no cells with filled nuclei. We further examined the effect of long-term trans- 

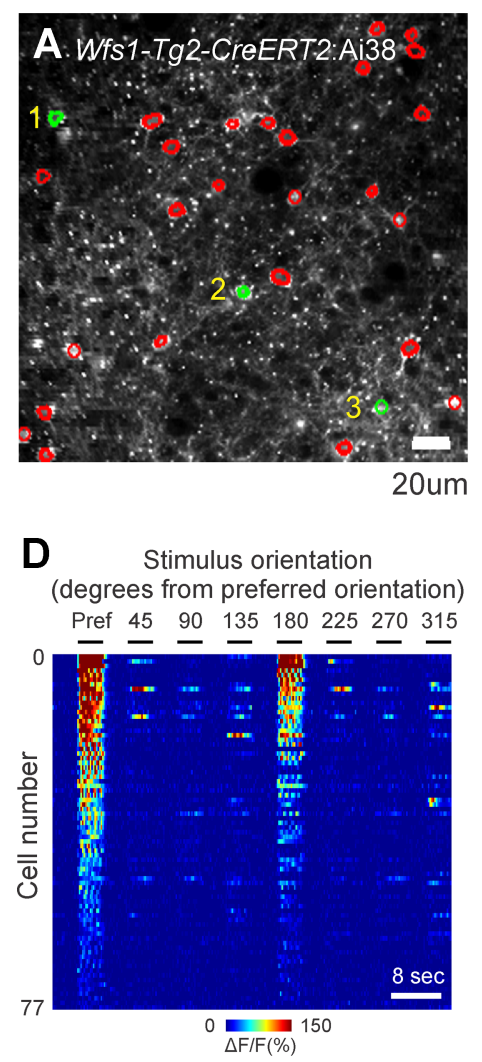

\section{$E$}

Normalized Fourier spectra of $\Delta F / F(t)$ during pref. stim
C

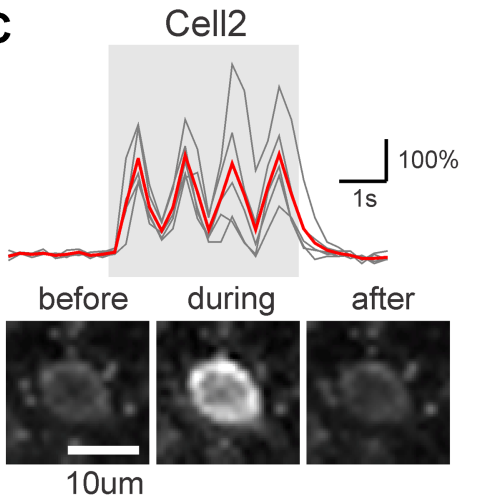

$\mathbf{F}$

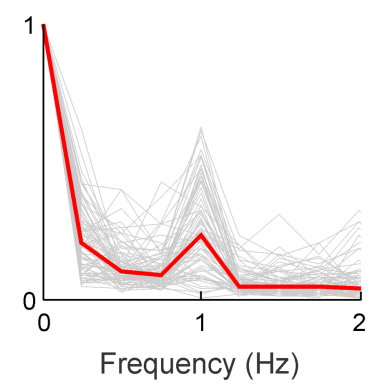

Average of all visual responses with $\Delta \mathrm{F} / \mathrm{F}_{\text {stim_end }}>25 \%$ (320 transients, 65 cells)
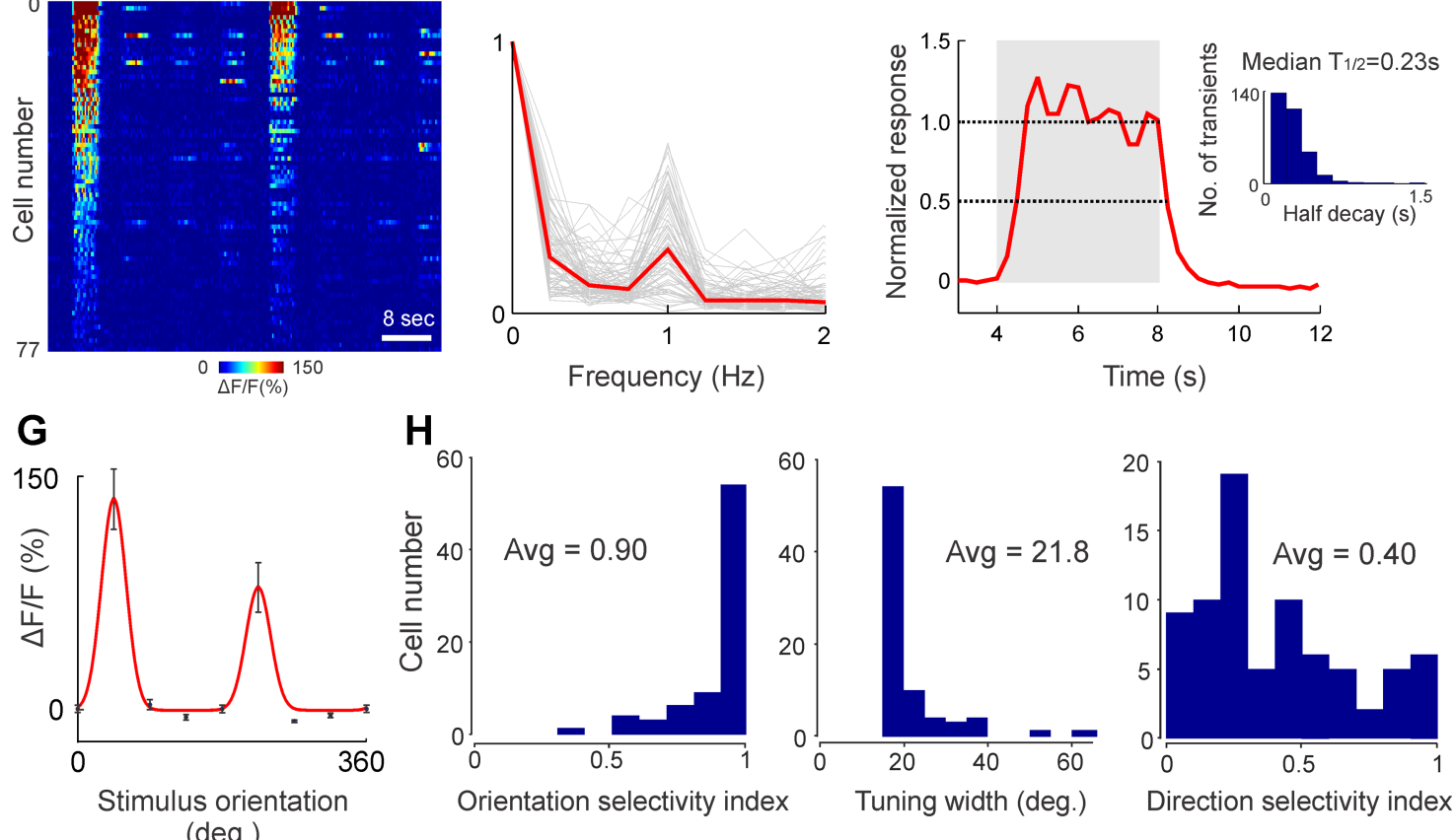

H

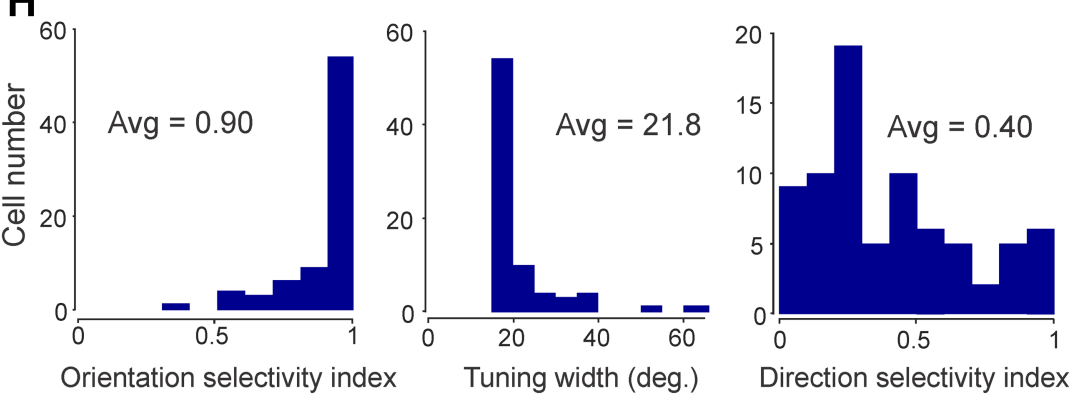

Figure 3. GCaMP3 imaging in Ai38 mice in the visual cortex. A, Native in vivo GCaMP3 fluorescence of layer 2/3 cells in a Wf51-Tg2-CreERT2:Ai38 mouse (160 $\mu \mathrm{m}$ below the pial surface). Regions of interest covering cytosolic regions of the cells were marked in red or green. $\boldsymbol{B}$, Responses of three example cells (marked green in $A$ ) to eight oriented grating stimuli. $\boldsymbol{C}$, Fluorescence change of a cell (cell 2 in $A$ and $B$ ) before, during, and after visual stimulation at the preferred orientation. $D$, Visual responses $(\Delta F / F)$ of 77 responsive cells, rank ordered by signal level, to eight angles aligned in columns starting with preferred angle. $E$, Fourier spectra of $\Delta F / F(t)$ during the presentation of pref. stimuli. Gray, Individual cells; red, median across cells. $F$, Average of 320 visual responses from 65 cells normalized to stimulus offset. Inset, Distribution of half-decay times $\left(T_{1 / 2}\right)$ from all responses. G, Orientation tuning of a neuron fitted with sum of two Gaussians (see Materials and Methods). $H, O S I$, tuning width, and DSI of visually responsive cells.

genic GCaMP3 expression in the Wfs1-Tg2-CreERT2:Ai38 cross. GCaMP3 expression was induced by tamoxifen at P7, and cortical tissue was examined 5 and 10 months after induction. In both cases, we found virtually no cells with filled nuclei (Fig. $2 A, B$ ), and the brightness of cytosolic GCaMP3 was comparable between 5 and 10 months (Fig. 2E). In contrast, filled neurons started to appear 3-4 weeks after AAV mediated GCaMP3 expression (Fig. $2 \mathrm{C}$, arrows), and 8 months after injection most cells were brightly labeled $(\sim 5.5$-fold brighter than at 4 weeks; Fig. $2 E$ ) with strong nuclear fluorescence (Fig. 2D). The baseline GCaMP3 fluorescence was $\sim 14$-fold brighter with AAV than with the Ai38 reporter mouse (Fig. 2E). We further determined the intracellular GCaMP3 concentration in Emx1-Cre:Ai38 cortical slices (see Materials and Methods). The intracellular GCaMP3 concentration was low $(5.4 \pm 1.0 \mu \mathrm{M} ; n=9)$. Thus, control of GCaMP3 expression might permit long-term expression with minimal adverse effects.

The $W f f_{1} 1-T g 2-C r e E R T 2$ line labels $\sim 40 \%$ of the excitatory cells in cortical layer 2/3 (Fig. 1B). This is unlike the Emx1-Cre line, which labels almost all excitatory neurons in the cortex (Fig. 1C), including deeper layers (Madisen et al., 2010). Because of these differences in labeling, the Wfs1-Tg2-CreERT2 line shows reduced nonspecific signal due to the densely labeled neuropil (Fig. 2A), and we therefore used this mouse for in vivo measurements in the primary visual cortex.

Wfs $1^{+}$neurons show highly tuned GCaMP3 responses Adult $W f_{s} 1-T g 2-C r e E R T 2: A i 38$ mice were anesthetized and implanted with a cranial window above primary visual cortex (V1) 
A

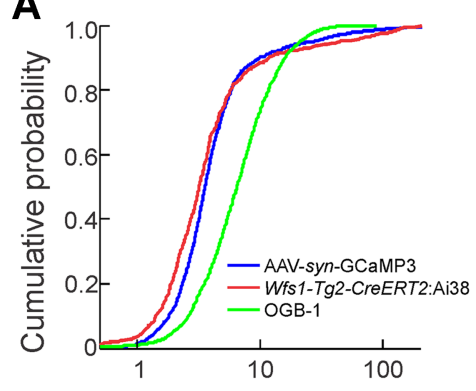

mean $\triangle F / F$ at pref. orientation (\%)
B

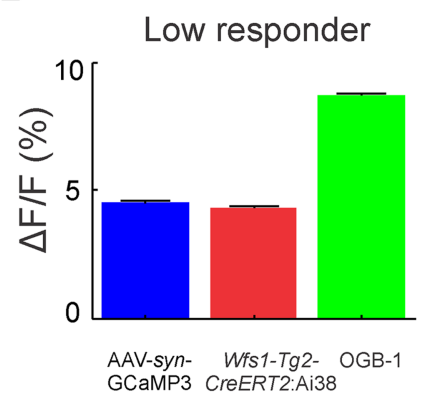

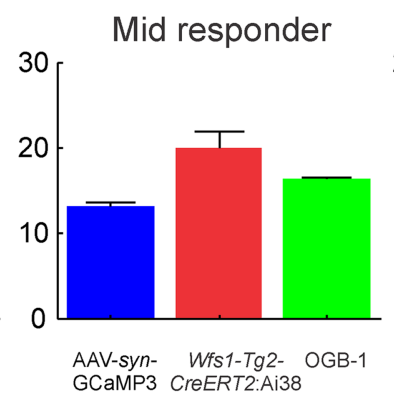

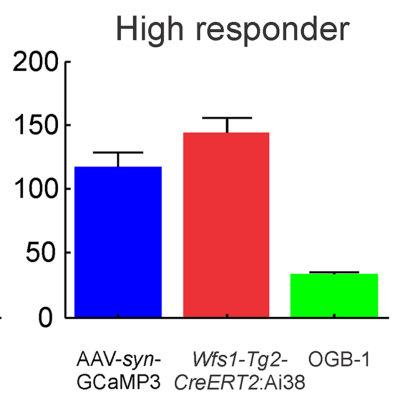

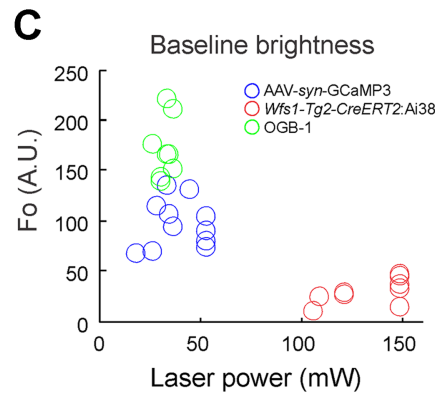
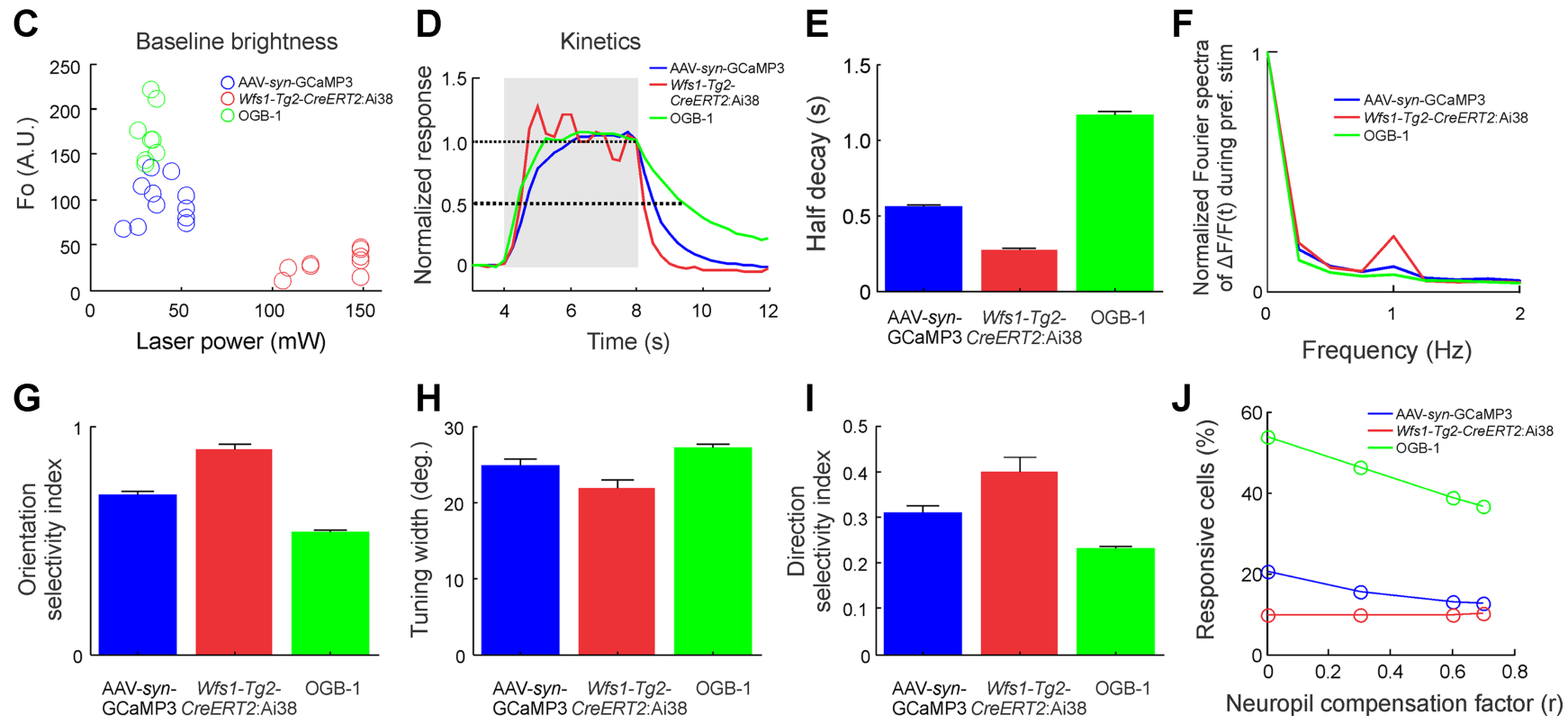

Figure 4. Comparison of visual cortical responses for different GCaMP3 delivery methods and the synthetic calcium indicator $0 G B-1 . A$, Distribution of response amplitude ( $\triangle F / F)$ at the preferred orientation. $B$, Average $\Delta F / F$ at preferred orientation for low responder (50th to 80th percentile), mid responder (80th to 97th percentile), and high responder ( $>97$ th percentile). $C$, Baseline brightness as a function of laser power. Each data point shows averaged baseline fluorescence of all cells in a given field ( $90-160 \mu \mathrm{m}$ below the pial surface). $\boldsymbol{D}$, Averaged visually evoked calcium transients normalized to the end of the stimulus period. $\boldsymbol{E}$, Half fluorescence decay time. $\boldsymbol{F}$, Fourier spectra of $\Delta F / F(t)$ during the presentation of pref. stimuli. $\mathbf{G}-\mathbf{I}$, Averaged 0 SI, tuning width, and DSI for all visually responsive neurons. J, Percentage of visually responsive cells as a function of neuropil compensation factor $r$ (see Materials and Methods). Error bars correspond to SEM.

immediately before in vivo imaging. Mice were presented with oriented gratings moving in eight different directions.

Two-photon imaging revealed subsets of GCaMP3-positive neurons showing highly selective responses to oriented gratings (Fig. 3A, B, G). The orientation tuning of these cells was consistent with previous experiments where $W f_{s} 1^{+}$cells were identified based on tdTomato expression in the Ai9 reporter mouse line (Madisen et al., 2010) and loaded with OGB-1 (Zariwala et al., 2011). A majority of the responsive neurons were modulated at the temporal frequency of the moving gratings $(1 \mathrm{~Hz})$ (Fig. $3 B, C, E)$, consistent with a predominance of simple cells in layer 2/3 of mouse V1 (Mangini and Pearlman, 1980; Niell and Stryker, 2008; Liu et al., 2010; Smith and Häusser, 2010). Significant GCaMP3 responses (ANOVA, $p<0.01$ ) were observed in $\sim 10 \%$ of GCaMP3-positive cells ( 77 of 773 cells in 3 mice), with a range of $1-25 \%$ across 29 fields of view at depths ranging from 110 to $250 \mu \mathrm{m}$ (Fig. 3D). The percentage of visually responsive $W f_{s} 1$ $\mathrm{GCaMP}^{+}$cells was lower than that reported in previous studies using OGB-1 (Zariwala et al., 2011). This likely reflects a lower sensitivity of GCaMP3 to weak activity (one to three action potentials per $0.5 \mathrm{~s}$ bin) (Tian et al., 2009) than OGB-1. The responding cells, however, often showed strong fluorescence changes (up to $400 \%$; Fig. $3 B$, cell 2). Overall, the average $\Delta F / F$ of the cells at the preferred orientation showed a skewed distribution (Fig. $4 A$, all 773 cells).

The decay time of GCaMP3 fluorescence was determined as the time to half-decay of the transients after stimulus offset. To ensure robust $\mathrm{SNR}$, this analysis was confined to trials with $\Delta F / F$ at stimulus offset $\left(\Delta F / F_{\text {stim_end }}>25 \%\right)$. The median $T_{1 / 2}$ of these calcium responses was $230 \pm 70 \mathrm{~ms}(n=320$ trials in 65 cells, SD; Fig. $3 F$ ). These decays are faster than those measured in previous studies using OGB-1 in V1 (Kerlin et al., 2010; Smith and Häusser, 2010) and Fluo-4 in the somatosensory cortex (Sato et al., 2007). The GCaMP3 signal in the Ai38 mouse permitted us to resolve the phasic excitation at the drifting frequency during individual stimulus presentations (Fig. $3 B, C$ ). Spectral analysis of the response waveform showed a clear peak at the drifting frequency $(1 \mathrm{~Hz})$ (Fig. 3E). Such modulations are hardly resolved in OGB-1 experiments (Fig. 4F) (Ohki et al., 2005; Mrsic-Flogel et al., 2007; Kerlin et al., 2010; Zariwala et al., 2011).

We quantified the tuning properties of cells that showed significant visually driven responses ( 77 cells). For each responsive neuron, we measured the average $\Delta \mathrm{F} / \mathrm{F}$ response at each orientation and fitted the response with a sum of two Gaussian functions (Fig. 3G) (see Materials and Methods) (Niell and Stryker, 2008). The OSI, tuning width, and DSI were calculated from the fitting 
A

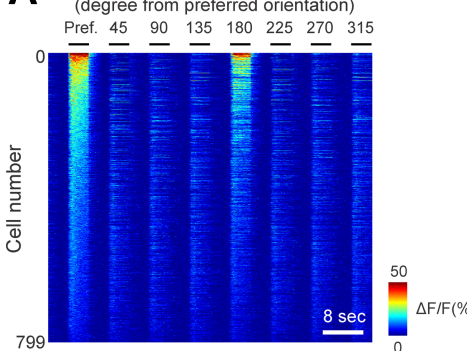

B

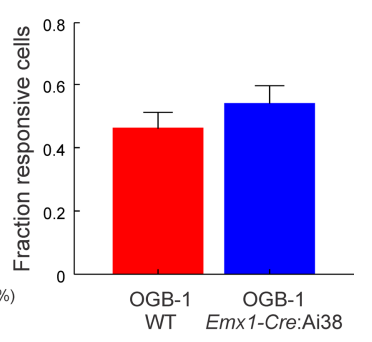

Figure 5. Visual cortical dynamics are not perturbed by long-term expression of GCaMP3 in Ai38 mice. $A, 0 G B-1$ responses ( $\triangle F / F)$ of 799 visually responsive cells to eight angles aligned in columns starting with the preferred angle in Emx1-Cre:Ai38 mice. $\boldsymbol{B}$, Comparison of the fraction of visually responsive cells recorded in wild-type (WT) mice with Emx1-Cre:Ai38 mice using 0GB-1-AM dye.

parameters (Fig. $3 H$ ). Visually responsive cells showed high orientation selectivity (mean $\pm \mathrm{SD}$, OSI, $0.90 \pm 0.14$ ), sharp tuning (mean $\pm \mathrm{SD}$, tuning width, $21.8 \pm 9.6^{\circ}$ ) and a broad distribution of direction selectivity (mean $\pm \mathrm{SD}$, DSI, $0.4 \pm 0.28$ ). These properties are consistent with previously reported tuning properties in identified excitatory neurons in V1 using electrophysiology (Niell and Stryker, 2008; Liu et al., 2009) and OGB-1 imaging (Kerlin et al., 2010; Zariwala et al., 2011).

\section{Comparison of GCaMP3 and OGB-1 in V1}

On average, a lower percentage of $W f_{s} 1^{+}$neurons showed significant responses to visual stimuli compared with studies using bulk loading of OGB-1-AM. For a direct comparison, we performed OGB-1 imaging in wild-type mice under identical stimulus and imaging conditions. Similar experiments were also performed with AAV-mediated GCaMP3 expression (see Materials and Methods).

The percentage of cells that were significantly visually responsive was $\sim 10 \%$ for Wfs1-Tg2-CreERT2:Ai38 (77 of 773 cells; three animals), $\sim 46 \%$ for OGB-1 (1673 of 3623 cells; three animals), and $\sim 16 \%$ for AAV-syn-GCaMP3 (277 of 1762 cells; four animals). Of the responsive cells, the percentage of cells with significant orientation selectivity (ANOVA across eight orientations, $p<0.01$ ) was $\sim 78 \%$ for $W f_{s} 1-T g 2-C r e E R T 2$ :Ai38 (60 of 77 ), $\sim 48 \%$ for OGB-1 (807 of 1673 ), and $\sim 45 \%$ for AAV-synGCaMP3 (126 of 227). The median fluorescence change at the preferred orientation was higher in OGB-1-labeled neurons than for GCaMP3 (Fig. $4 A$ ). However, the maximum $\Delta F / F$ achieved in GCaMP3-expressing neurons was substantially higher (Fig. 4A). Whereas OGB-1 provided a higher average signal for low responders (cells that fall within the 50th to 80th percentile of the $\Delta F / F$ distribution), among the top responders ( $>97$ th percentile) GCaMP3 did considerably better (Fig. $4 B$ ). The percentage of GCaMP3-responsive cells was slightly higher with AAV than with the Ai38 reporter mouse. This is likely due to significantly higher expression levels and brightness of GCaMP3-expressing neurons in the case of viral expression (Fig. 4C), providing greater SNR.

The total laser power (at $\lambda=900 \mathrm{~nm}$ ) used for AAV-syn-GCaMP3 experiments was substantially lower than that used for GCaMP3 imaging from the Ai38 reporter mouse, yet AAV-syn-GCaMP3 cells show significantly brighter baseline fluorescence (Fig. $4 C$ ). This reflects the lower expression of GCaMP3 in the Ai38 line (heterozygous for GCaMP3 in this study) compared with that achieved with AAV. The GCaMP3 decay kinetics using either expression system are significantly faster than for bulk-loaded OGB-1 (median $\pm \mathrm{SD}, T_{1 / 2}=510 \pm 320 \mathrm{~ms}$ for AAV-syn-GCaMP3, $230 \pm$
$160 \mathrm{~ms}$ for $W f_{s} 1-T g 2-C r e E R T 2: A i 38$, and $1150 \pm 520 \mathrm{~ms}$ for OGB-1; Fig. 4D). Interestingly, GCaMP3 responses in the Ai38 line were significantly faster than those recorded after AAV-mediated expression ( $p<0.001$; unpaired $t$ test; Fig. $4 D, E)$. The phasic excitation at the drifting frequency $(1 \mathrm{~Hz})$ was better resolved using $W f_{s} 1-T g 2-C r e E R T 2: A i 38$ compared with AAV-syn-GCaMP3 and OGB-1 (Fig. 4F). The faster kinetics likely reflects reduced calcium buffering (Neher, 1995; Helmchen et al., 1996; Hires et al., 2008) due to the lower GCaMP3 expression level in the Ai38 line.

The OSI, tuning width, and DSI of the visually responsive cells across the two GCaMP3 expression systems was then compared with those obtained in OGB-1 imaging (Fig. 4G-I). The mean OSI for Wfs1-Tg2-CreERT2:Ai38 cells was markedly higher $(0.90 \pm 0.14)$ compared with AAV-syn-GCaMP3 (0.70 \pm 0.27$)$ and OGB-1 (0.53 \pm 0.27$)$ (Fig. $4 G)$. A possible explanation is that the $W f_{s} 1-T g 2-C r e E R T 2: A i 38$ selectively labels excitatory neurons, whereas in OGB-1 and AAV-syn-GCaMP3 the labeling includes inhibitory neurons known to show weaker or no orientation selectivity (Sohya et al., 2007; Niell and Stryker, 2008; Liu et al., 2009; Kerlin et al., 2010; Zariwala et al., 2011). Furthermore, the contamination of signal due to nonspecific neuropil responses (Kerr et al., 2005) can lower the orientation selectivity of neurons. Wfs1-Tg2-CreERT2:Ai38 animals showed sparser labeling (Fig. 1C) compared with AAV-syn-GCaMP3 and OGB-1 and therefore could be less susceptible to neuropil contamination. Indeed, compensating nonspecific neuropil signals reduced the percentage of responsive neurons for AAV-syn-GCaMP3 and OGB-1, but had minimal effect on Wfs1-Tg2-CreERT2:Ai38 (Fig. $4 J$ ). Finally, GCaMP3 may fail to detect some weak responses at nonpreferred orientations. This can lead to an overestimation of the orientation selectivity in GCaMP3 experiments. The inclusion of poorly selective neurons in OGB-1 and AAV-synGCaMP3 imaging is also reflected in the comparison of both tuning width and DSI of neurons across these experiments (Fig. $4 H, I)$. The highly selective responses of GCaMP3-expressing cells in Ai38 mice demonstrate that long-term expression of GCaMP3 at low, steady-state levels likely does not impact the functional tuning properties of the neurons imaged in this study.

Together, these results indicate that GCaMP3-responsive cells show orientation and direction preference typical for visual cortical neurons. The Ai38 reporter mouse gave lower signal and faster kinetics, but the functional properties of the neurons imaged appear normal compared with those following AAV infection or OGB-1 bulk loading.

\section{OGB-1 responses in neurons expressing GCaMP3}

The lower percentage of visually responsive neurons in GCaMP3 compared with OGB-1 experiments might be due to adverse effects of GCaMP3 expression. To test this possibility, we performed OGB-1 imaging in a mouse where GCaMP3 was expressed in the majority of cortical neurons throughout development. Emx1 is a marker for cortical excitatory neurons (Chan et al., 2001), and this expression pattern is recapitulated in the Emx1-Cre transgenic mouse line (Gorski et al., 2002). The Emx1-Cre mouse was crossed with the Ai38 line to produce expression of GCaMP3 in all cortical excitatory neurons. Adult Emx1-Cre:Ai38 mice were prepared for OGB-1 imaging in an identical manner to the OGB-1 recordings in wild-type mice. Imaging was performed at $800 \mathrm{~nm}$ to excite OGB-1, while minimizing GCaMP3 fluorescence.

The percentage of responsive cells, decay kinetics, and tuning properties of OGB-1-loaded neurons in Emx1-Cre:Ai38 mice was similar to that observed with OGB-1 imaging in wild-type mice (Fig. 
$5 A)$. The fraction of visually responsive cells from Emx1-Cre:Ai38 mice was 54\% (799 of 1482 cells; range, $33-86 \%$ across 10 fields of view) compared with $\sim 46 \%$ in wild-type mice (1673 of 3623 cells; range, 10-97\% across 23 fields of view) (Fig. 5B). The OSI $(0.53 \pm 0.24)$, tuning width $\left(28 \pm 15^{\circ}\right)$, and DSI $(0.21 \pm 0.17)$ of OGB-1-labeled neurons in Emx1-Cre:Ai38 mice was not different from OGB-1 imaging in wild-type mice (OSI, $0.53 \pm 0.27$; TW, $27 \pm 15^{\circ}$; DSI, $0.23 \pm 0.19)(p>0.1$, unpaired $t$ test $)$. These results indicate that Ai38-mediated GCaMP3 expression does not impair the responsiveness, tuning properties, or calcium handling of neurons.

\section{Functional imaging in the developing} and adult retina

Ai38 crossed with Chat-Cre showed retinal GCaMP3 expression exclusively in starburst amacrine cells (SACs) (Fig. 1G), consistent with known expression patterns (Ivanova et al., 2010). Synchronized, periodic calcium transients in starburst amacrine cells are a well known but incompletely understood feature of the developing vertebrate retina (Feller et al., 1996; Zhou, 1998; Wong, 1999; Zheng et al., 2006). Two-photon fluorescence imaging from SAC populations in a P8 Chat-Cre:Ai38 retina (Fig. 6A) showed large, periodic calcium transients on either side of the inner plexiform layer (Fig. 6B). Temporal delays in the activation of individual cells within the field of view were consistent with a traveling wave (Fig. $6 A, B$; arrowhead in Fig. $6 A$ indicates the direction of wave propagation).

Ai38 crossed with Pvalb-2A-Cre mice showed GCaMP3 expression in ganglion cells, horizontal cells, and Müller glia (Figs. $1 F, 6 C, 7 A, B)$, consistent with known expression patterns (Kim and Jeon, 2006). In the adult retina, light stimulation evoked robust calcium responses in GCaMP3-expressing ganglion cells (Fig. 6C,D), but not in Müller glia (data not shown). Light evoked ganglion cell responses matched responses recorded with virally transduced GCaMP3, reported previously [AAV-synGCaMP3 (Borghuis et al., 2011)]. Oscillatory electrical field potentials ( $1 \mathrm{kHz}, 20 \mathrm{nA}$ peak current, $500 \mathrm{~ms}$ duration), delivered to the ganglion cell layer through a patch pipette $(\sim 3 \mathrm{M} \Omega)$, evoked robust calcium responses in ganglion cells and also in Müller glia (Müller glia peak $\Delta F / F>6$; Fig. 7).

GCaMP3 responses in the cerebellum of Pcp2-Cre:Ai38 mice In Pcp2-Cre:Ai38 mice, fluorescence microscopy confirmed high levels of expression in Purkinje cells (PCs) of the cerebellum (Fig. 1D). GCaMP3 expression appeared to be localized exclusively to PCs with nearly all PCs labeled. PC dendritic arbors, somata, and proximal axons could be clearly discerned, suggesting expression levels sufficient for functional imaging (Fig. 8A-C).

Climbing fibers generate all-or-none complex spikes and dendritic calcium transients in PCs with a frequency of $<1 \mathrm{~Hz}$ in lightly anesthetized mice (Ozden et al., 2009; Schultz et al., 2009),
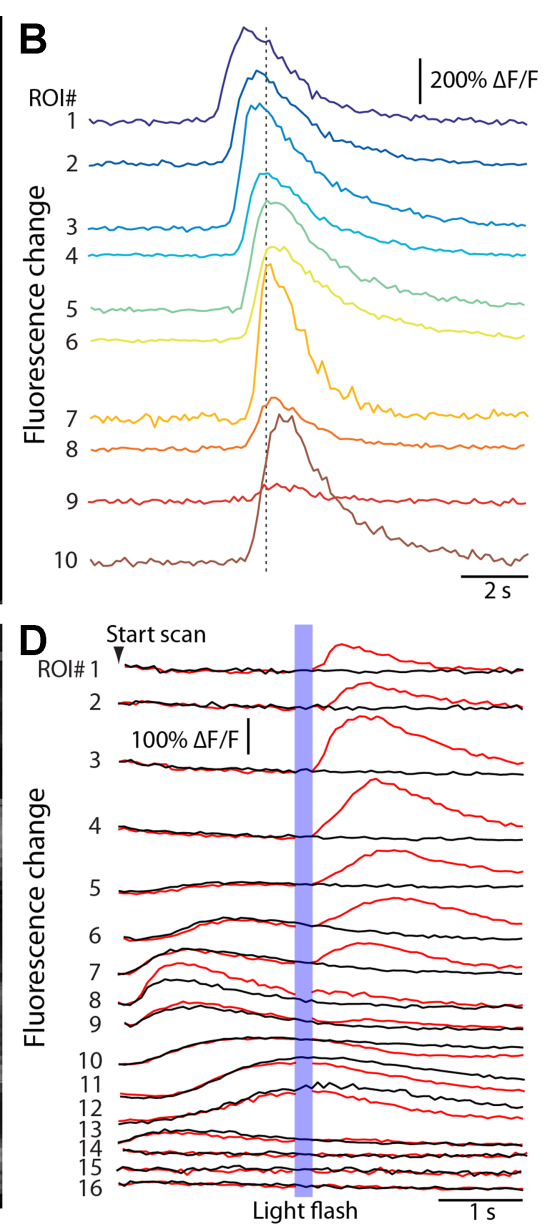

Light flash

Figure 6. Neuronal dynamics in genetically targeted neurons in the retina from Ai38 mice. A, Two-photon image of GCaMP3expressing starburst amacrine cells in the ganglion cell layer of Chat-Cre:Ai38 mice at postnatal day 8 . The arrowhead indicates the approxshow transient calcium increases with SNR of $\sim 100$. Rise time of the activation was temporally offset across the cell population (dotted line 列e by a visible light flash (LED, $458 \mathrm{~nm}, 100 \mathrm{~ms}$ duration; indicated with blue bar); in the other $50 \%$ (black traces), no flash was presented. Most cells responded to the scan laser [due to activation of the photoreceptors underlying the scanned region (Borghuis et al., 2011)], or to the brief visible light flash, or both. Each trace represents the average response of 10 trials.

whereas cerebellar granule cells can also induce subdendritic signals that span only part of the PC arbor (Wang et al., 2000). Under light anesthesia (0.75-1.0\% isoflurane), we observed sparse but clearly visible fluorescence transients in one or a few isolated $\mathrm{PC}$ arbors at a rate of $<1 \mathrm{~Hz}$ (Fig. 8D,F). We also observed large amplitude $(>100 \% \Delta F / F)$ subdendritic signals that spanned a few PC branchlets (Fig. $8 E$ ). Mean amplitudes for all transients $(n=611$ in 3 mice) were $30 \pm 11 \% \Delta F / F$ (mean \pm SEM; range, $9-260 \% \Delta F / F)$. The low frequency of events compared with previous studies using OGB-1 (Ozden et al., 2009) could result from the high levels of the endogenous calcium binding proteins calbindin D28K and parvalbumin in PCs (Celio, 1990; Baimbridge et al., 1992), and slower calcium binding to GCaMP3 compared with OGB-1. Calbindin limits calcium concentration increases in response to single complex spikes to a few hundred nanomolar (Schmidt et al., 2003). This falls in the lower range of what GCaMP3 can detect (Tian et al., 2009).

\section{Discussion}

The sensitivity and kinetics of GCaMP3 make it a promising GECI for in vivo imaging of neuronal activity in a variety of different brain 

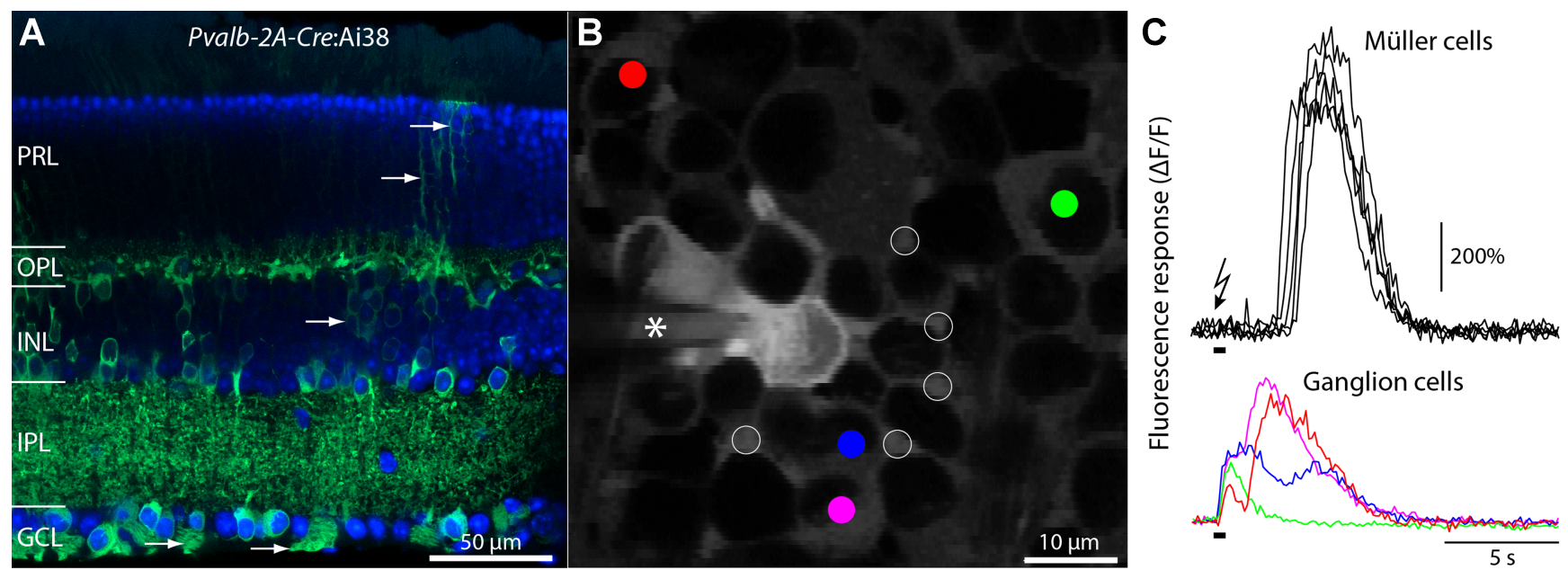

Figure 7. Electrical stimulation evokes robust calcium responses in Müller glia from Ai38 mice. $A, A i 38$ crossed with Pvalb-2A-Cre expressed GCaMP3 in several retinal neuron types and also in Müller glia (arrows). PRL, Photoreceptor layer; OPL, outer plexiform layer; INL, inner nuclear layer; IPL, inner plexiform layer; GCL, ganglion cell layer. $\boldsymbol{B}$, Two-photon fluorescence image of the ganglion cell layer in an adult Pvalb-2A-Cre:Ai38 retina. The field of view includes several ganglion cells (colored circles), and also Müller glia processes (open circles). The electrical stimulus (see text) was delivered to the ganglion cell layer through a patch pipette (asterisk). $\boldsymbol{C}$, Fluorescence responses of the Müller glia processes and the ganglion cells annotated in B. Each trace represents the change in fluorescence intensity referenced to the fluorescence intensity at scan onset. The electrical stimulus (timing indicated by black bar) was delivered $>5 \mathrm{~s}$ after scan onset. Ganglion cell responses preceded the glial cell response by $>1 \mathrm{~s}$.
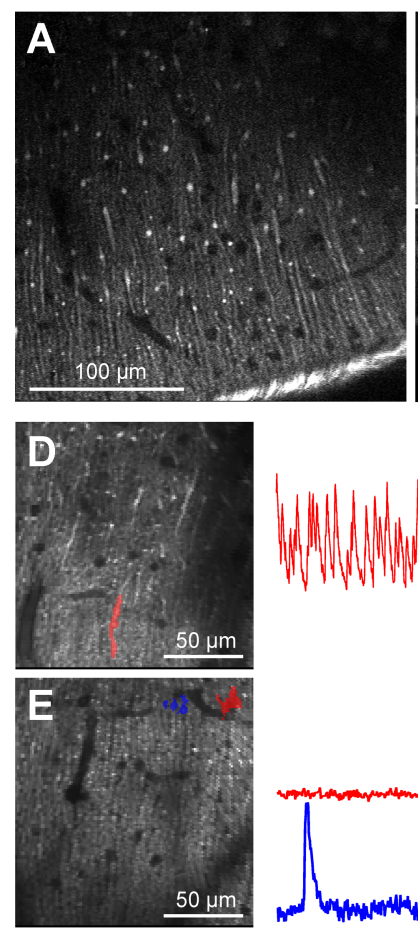
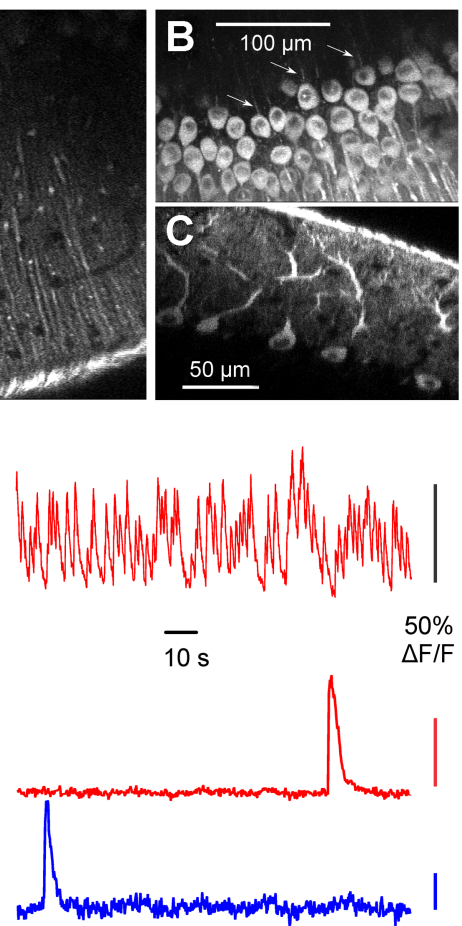
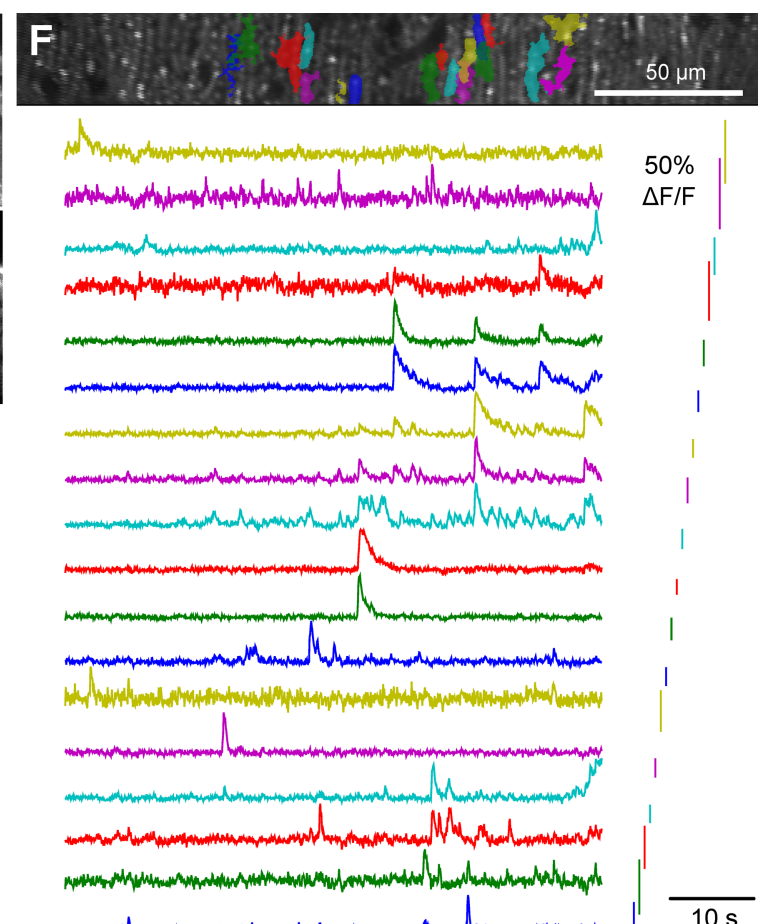

$10 \mathrm{~s}$

Figure 8. GCaMP3 expression patterns and functional signals in Pcp2-Cre:Ai38 mice. A, Single optical section (xy plane) in the cerebellum showing GCaMP3 expression pattern in the molecular layer of a Pcp2-Cre:Ai38 mouse. B, Maximum projection image (xy plane) of the Purkinje cell layer. The arrows denote Purkinje cell axons. C, Single optical section (xz plane) showing Purkinje cell somata and their dendrites. $\boldsymbol{D}$, Responses from an isolated dendrite showing calcium transients at low rate $(\sim 0.5 \mathrm{~Hz})$. $\boldsymbol{E}$, Subdendritic signals at two regions of interest defined by independent component analysis (ICA) (Hyvärinen, 1999). $\boldsymbol{F}$, Various signals recorded from PC dendrites (ROls selected with ICA are sorted left-to-right, and signals bottom-to-top).

regions and organisms (Tian et al., 2009; Dombeck et al., 2010; O'Connor et al., 2010; Seelig et al., 2010; Borghuis et al., 2011). The Ai38 mouse now facilitates labeling of genetically defined populations of neurons with GCaMP3. The possibilities are mainly limited by the available Cre driver lines, the number of which is rapidly expanding (http://nagy.mshri.on.ca/cre_new/). Ai38 yielded homogeneous and stable expression levels over many months. Cell morphology, physiology, and response properties appeared unchanged during this time. This stable expression will greatly enable chronic imaging experiments, for which the time window provided by AAV expression is insufficient. The low (undetectable) cytomorbidity indicates that usable GCaMP3 concentrations can be tolerated longterm. Head-to-head comparison of Ai38 with AAV-syn-GCaMP3 and OGB-1 showed similar fluorescent response properties in vivo, with the former having superior temporal resolution.

The homogeneous and repeatable expression will permit easier pooling of imaging results across multiple experiments. For the crosses evaluated here, the expression levels in the retina ap- 
peared to match the average expression levels obtained with viral transduction (Borghuis et al., 2011), and no increase in laser power was required to image those cells. However, high laser powers were required for cortical imaging in the Ai38 mouse. Higher expression levels might be required for some applications. Breeding mice homozygous for the GCaMP3 allele should increase the expression level. Further optimization of transgenic strategies should improve the expression level while preserving low cytomorbidity.

GCaMP3 is not the perfect calcium indicator. Further engineering of the GCaMP scaffold, or of other GECI scaffolds, will be required to achieve the sensitivity, kinetics, and SNR levels required to robustly detect very sparse neural activity in vivo. The expression and targeting cassette used here, as well as the standardized imaging assays established, will be useful for creating reporter mice from the next generation of GECIs as well. As GECI sensitivity to single spikes improves, we expect that the performance of the resulting transgenic mice in standardized assays such as the V1 experiment presented here will approach that of the best small molecule indicators.

\section{References}

Andermann ML, Kerlin AM, Reid RC (2010) Chronic cellular imaging of mouse visual cortex during operant behavior and passive viewing. Front Cell Neurosci 4:3.

Atkin SD, Patel S, Kocharyan A, Holtzclaw LA, Weerth SH, Schram V, Pickel J, Russell JT (2009) Transgenic mice expressing a cameleon fluorescent $\mathrm{Ca}^{2+}$ indicator in astrocytes and Schwann cells allow study of glial cell $\mathrm{Ca}^{2+}$ signals in situ and in vivo. J Neurosci Methods 181:212-226.

Baimbridge KG, Celio MR, Rogers JH (1992) Calcium-binding proteins in the nervous system. Trends Neurosci 15:303-308.

Barski JJ, Dethleffsen K, Meyer M (2000) Cre recombinase expression in cerebellar Purkinje cells. Genesis 28:93-98.

Borghuis BG, Tian L, Xu Y, Nikonov SS, Vardi N, Zemelman BV, Looger LL (2011) Imaging light responses of targeted neuron populations in the rodent retina. J Neurosci 31:2855-2867.

Brainard DH (1997) The Psychophysics Toolbox. Spat Vis 10:433-436.

Celio MR (1990) Calbindin D-28k and parvalbumin in the rat nervous system. Neuroscience 35:375-475.

Chan CH, Godinho LN, Thomaidou D, Tan SS, Gulisano M, Parnavelas JG (2001) Emx1 is a marker for pyramidal neurons of the cerebral cortex. Cereb Cortex 11:1191-1198.

Chen TW, Lin BJ, Schild D (2009) Odor coding by modules of coherent mitral/tufted cells in the vertebrate olfactory bulb. Proc Natl Acad Sci U S A 106:2401-2406.

Díez-García J, Matsushita S, Mutoh H, Nakai J, Ohkura M, Yokoyama J, Dimitrov D, Knöpfel T (2005) Activation of cerebellar parallel fibers monitored in transgenic mice expressing a fluorescent $\mathrm{Ca}^{2+}$ indicator protein. Eur J Neurosci 22:627-635.

Dombeck DA, Khabbaz AN, Collman F, Adelman TL, Tank DW (2007) Imaging large-scale neural activity with cellular resolution in awake, mobile mice. Neuron 56:43-57.

Dombeck DA, Harvey CD, Tian L, Looger LL, Tank DW (2010) Functional imaging of hippocampal place cells at cellular resolution during virtual navigation. Nat Neurosci 13:1433-1440.

Feil R, Wagner J, Metzger D, Chambon P (1997) Regulation of Cre recombinase activity by mutated estrogen receptor ligand-binding domains. Biochem Biophys Res Commun 237:752-757.

Feller MB, Wellis DP, Stellwagen D, Werblin FS, Shatz CJ (1996) Requirement for cholinergic synaptic transmission in the propagation of spontaneous retinal waves. Science 272:1182-1187.

Gorski JA, Talley T, Qiu M, Puelles L, Rubenstein JL, Jones KR (2002) Cortical excitatory neurons and glia, but not GABAergic neurons, are produced in the Emx1-expressing lineage. J Neurosci 22:6309-6314.

Grinvald A, Hildesheim R (2004) VSDI: a new era in functional imaging of cortical dynamics. Nat Rev Neurosci 5:874-885.

Grynkiewicz G, Poenie M, Tsien RY (1985) A new generation of $\mathrm{Ca}^{2+}$ indicators with greatly improved fluorescence properties. J Biol Chem 260:3440-3450.
Harvey CD, Ehrhardt AG, Cellurale C, Zhong H, Yasuda R, Davis RJ, Svoboda K (2008) A genetically encoded fluorescent sensor of ERK activity. Proc Natl Acad Sci U S A 105:19264-19269.

Hasan MT, Friedrich RW, Euler T, Larkum ME, Giese G, Both M, Duebel J, Waters J, Bujard H, Griesbeck O, Tsien RY, Nagai T, Miyawaki A, Denk W (2004) Functional fluorescent $\mathrm{Ca}^{2+}$ indicator proteins in transgenic mice under TET control. PLoS Biol 2:e163.

Heim N, Garaschuk O, Friedrich MW, Mank M, Milos RI, Kovalchuk Y, Konnerth A, Griesbeck O (2007) Improved calcium imaging in transgenic mice expressing a troponin C-based biosensor. Nat Methods 4: 127-129.

Helmchen F, Imoto K, Sakmann B (1996) $\mathrm{Ca}^{2+}$ buffering and action potential-evoked $\mathrm{Ca}^{2+}$ signaling in dendrites of pyramidal neurons. Biophys J 70:1069-1081.

Hires SA, Tian L, Looger LL (2008) Reporting neural activity with genetically encoded calcium indicators. Brain Cell Biol 36:69-86.

Hyvärinen A (1999) Fast and robust fixed-point algorithms for independent component analysis. IEEE Trans Neural Netw 10:626-634.

Ivanova E, Hwang GS, Pan ZH (2010) Characterization of transgenic mouse lines expressing Cre recombinase in the retina. Neuroscience 165: 233-243.

Kerlin AM, Andermann ML, Berezovskii VK, Reid RC (2010) Broadly tuned response properties of diverse inhibitory neuron subtypes in mouse visual cortex. Neuron 67:858-871.

Kerr JN, Greenberg D, Helmchen F (2005) Imaging input and output of neocortical networks in vivo. Proc Natl Acad Sci U S A 102:14063-14068.

Kim TJ, Jeon CJ (2006) Morphological classification of parvalbumincontaining retinal ganglion cells in mouse: single-cell injection after immunocytochemistry. Invest Ophthalmol Vis Sci 47:2757-2764.

Komiyama T, Sato TR, O'Connor DH, Zhang YX, Huber D, Hooks BM, Gabitto M, Svoboda K (2010) Learning-related fine-scale specificity imaged in motor cortex circuits of behaving mice. Nature 464:1182-1186.

Kügler S, Meyn L, Holzmüller H, Gerhardt E, Isenmann S, Schulz JB, Bähr M (2001) Neuron-specific expression of therapeutic proteins: evaluation of different cellular promoters in recombinant adenoviral vectors. Mol Cell Neurosci 17:78-96.

Liu BH, Li P, Li YT, Sun YJ, Yanagawa Y, Obata K, Zhang LI, Tao HW (2009) Visual receptive field structure of cortical inhibitory neurons revealed by two-photon imaging guided recording. J Neurosci 29:10520-10532.

Liu BH, Li P, Sun YJ, Li YT, Zhang LI, Tao HW (2010) Intervening inhibition underlies simple-cell receptive field structure in visual cortex. Nat Neurosci 13:89-96.

Lütcke H, Murayama M, Hahn T, Margolis DJ, Astori S, Zum Alten Borgloh SM, Göbel W, Yang Y, Tang W, Kügler S, Sprengel R, Nagai T, Miyawaki A, Larkum ME, Helmchen F, Hasan MT (2010) Optical recording of neuronal activity with a genetically-encoded calcium indicator in anesthetized and freely moving mice. Front Neural Circuits 4:9.

Madisen L, Zwingman TA, Sunkin SM, Oh SW, Zariwala HA, Gu H, Ng LL, Palmiter RD, Hawrylycz MJ, Jones AR, Lein ES, Zeng H (2010) A robust and high-throughput Cre reporting and characterization system for the whole mouse brain. Nat Neurosci 13:133-140.

Mangini NJ, Pearlman AL (1980) Laminar distribution of receptive field properties in the primary visual cortex of the mouse. J Comp Neurol 193:203-222.

Mank M, Griesbeck O (2008) Genetically encoded calcium indicators. Chem Rev 108:1550-1564.

Mank M, Santos AF, Direnberger S, Mrsic-Flogel TD, Hofer SB, Stein V, Hendel T, Reiff DF, Levelt C, Borst A, Bonhoeffer T, Hübener M, Griesbeck $\mathrm{O}$ (2008) A genetically encoded calcium indicator for chronic in vivo two-photon imaging. Nat Methods 5:805-811.

Mao T, O'Connor DH, Scheuss V, Nakai J, Svoboda K (2008) Characterization and subcellular targeting of GCaMP-type genetically-encoded calcium indicators. PLoS One 3:e1796.

Mao T, Kusefoglu D, Hooks BM, Huber D, Petreanu L, Svoboda K (2011) Long-range neuronal circuits underlying the interaction between sensory and motor cortex. Neuron 72:111-123.

Miyawaki A (2005) Innovations in the imaging of brain functions using fluorescent proteins. Neuron 48:189-199.

Miyawaki A, Llopis J, Heim R, McCaffery JM, Adams JA, Ikura M, Tsien RY (1997) Fluorescent indicators for $\mathrm{Ca}^{2+}$ based on green fluorescent proteins and calmodulin. Nature 388:882-887.

Mrsic-Flogel TD, Hofer SB, Ohki K, Reid RC, Bonhoeffer T, Hübener M 
(2007) Homeostatic regulation of eye-specific responses in visual cortex during ocular dominance plasticity. Neuron 54:961-972.

Muto A, Ohkura M, Kotani T, Higashijima S, Nakai J, Kawakami K (2011) Genetic visualization with an improved GCaMP calcium indicator reveals spatiotemporal activation of the spinal motor neurons in zebrafish. Proc Natl Acad Sci U S A 108:5425-5430.

Nagai T, Yamada S, Tominaga T, Ichikawa M, Miyawaki A (2004) Expanded dynamic range of fluorescent indicators for $\mathrm{Ca}^{2+}$ by circularly permuted yellow fluorescent proteins. Proc Natl Acad Sci U S A 101: 10554-10559.

Nakai J, Ohkura M, Imoto K (2001) A high signal-to-noise $\mathrm{Ca}^{2+}$ probe composed of a single green fluorescent protein. Nat Biotechnol 19:137-141

Neher E (1995) The use of Fura-2 for estimating Ca buffers and Ca fluxes. Neuropharmacology 34:1423-1442.

Niell CM, Stryker MP (2008) Highly selective receptive fields in mouse visual cortex. J Neurosci 28:7520-7536.

O'Connor DH, Peron SP, Huber D, Svoboda K (2010) Neural activity in barrel cortex underlying vibrissa-based object localization in mice. Neuron 67:1048-1061.

Ohki K, Chung S, Ch'ng YH, Kara P, Reid RC (2005) Functional imaging with cellular resolution reveals precise micro-architecture in visual cortex. Nature 433:597-603.

Orban PC, Chui D, Marth JD (1992) Tissue- and site-specific DNA recombination in transgenic mice. Proc Natl Acad Sci U S A 89:6861-6865.

Ozden I, Sullivan MR, Lee HM, Wang SS (2009) Reliable coding emerges from coactivation of climbing fibers in microbands of cerebellar Purkinje neurons. J Neurosci 29:10463-10473.

Palmer AE, Giacomello M, Kortemme T, Hires SA, Lev-Ram V, Baker D, Tsien RY (2006) $\mathrm{Ca}^{2+}$ indicators based on computationally redesigned calmodulin-peptide pairs. Chem Biol 13:521-530.

Pelli DG (1997) The VideoToolbox software for visual psychophysics: transforming numbers into movies. Spat Vis 10:437-442.

Pologruto TA, Sabatini BL, Svoboda K (2003) ScanImage: flexible software for operating laser-scanning microscopes. Biomed Eng Online 2:13.

Regehr WG, Tank DW (1991) Selective fura-2 loading of presynaptic terminals and nerve cell processes by local perfusion in mammalian brain slice. J Neurosci Methods 37:111-119.

Sato TR, Gray NW, Mainen ZF, Svoboda K (2007) The functional microarchitecture of the mouse barrel cortex. PLoS Biol 5:e189.

Sauer B, Henderson N (1988) Site-specific DNA recombination in mammalian cells by the Cre recombinase of bacteriophage P1. Proc Natl Acad Sci U S A 85:5166-5170.

Schmidt H, Stiefel KM, Racay P, Schwaller B, Eilers J (2003) Mutational analysis of dendritic $\mathrm{Ca}^{2+}$ kinetics in rodent Purkinje cells: role of parvalbumin and calbindin D28k. J Physiol 551:13-32.

Schultz SR, Kitamura K, Post-Uiterweer A, Krupic J, Häusser M (2009) Spatial pattern coding of sensory information by climbing fiber-evoked calcium signals in networks of neighboring cerebellar Purkinje cells. J Neurosci 29:8005-8015.

Seelig JD, Chiappe ME, Lott GK, Dutta A, Osborne JE, Reiser MB, Jayaraman V (2010) Two-photon calcium imaging from head-fixed Drosophila during optomotor walking behavior. Nat Methods 7:535-540.
Smith SL, Häusser M (2010) Parallel processing of visual space by neighboring neurons in mouse visual cortex. Nat Neurosci 13:1144-1149.

Sohya K, Kameyama K, Yanagawa Y, Obata K, Tsumoto T (2007) GABAergic neurons are less selective to stimulus orientation than excitatory neurons in layer II/III of visual cortex, as revealed by in vivo functional $\mathrm{Ca}^{2+}$ imaging in transgenic mice. J Neurosci 27:2145-2149.

Soriano P (1999) Generalized lacZ expression with the ROSA26 Cre reporter strain. Nat Genet 21:70-71.

Stosiek C, Garaschuk O, Holthoff K, Konnerth A (2003) In vivo two-photon calcium imaging of neuronal networks. Proc Natl Acad Sci U S A 100: 7319-7324.

Tallini YN, Ohkura M, Choi BR, Ji G, Imoto K, Doran R, Lee J, Plan P, Wilson J, Xin HB, Sanbe A, Gulick J, Mathai J, Robbins J, Salama G, Nakai J, Kotlikoff MI (2006) Imaging cellular signals in the heart in vivo: cardiac expression of the high-signal $\mathrm{Ca}^{2+}$ indicator GCaMP2. Proc Natl Acad Sci U S A 103:4753-4758.

Tallini YN, Brekke JF, Shui B, Doran R, Hwang SM, Nakai J, Salama G, Segal SS, Kotlikoff MI (2007) Propagated endothelial $\mathrm{Ca}^{2+}$ waves and arteriolar dilation in vivo: measurements in Cx40BAC GCaMP2 transgenic mice. Circ Res 101:1300-1309.

Thévenaz P, Ruttimann UE, Unser M (1998) A pyramid approach to subpixel registration based on intensity. IEEE Trans Image Process 7:27-41.

Tian L, Hires SA, Mao T, Huber D, Chiappe ME, Chalasani SH, Petreanu L, Akerboom J, McKinney SA, Schreiter ER, Bargmann CI, Jayaraman V, Svoboda K, Looger LL (2009) Imaging neural activity in worms, flies and mice with improved GCaMP calcium indicators. Nat Methods 6:875-881.

Tsien RY (1989) Fluorescent probes of cell signaling. Annu Rev Neurosci 12:227-253.

Tsien RY, Pozzan T, Rink TJ (1982) Calcium homeostasis in intact lymphocytes: cytoplasmic free calcium monitored with a new, intracellularly trapped fluorescent indicator. J Cell Biol 94:325-334.

Wang SS, Denk W, Häusser M (2000) Coincidence detection in single dendritic spines mediated by calcium release. Nat Neurosci 3:1266-1273.

Wong RO (1999) Retinal waves and visual system development. Annu Rev Neurosci 22:29-47.

Yasuda R, Harvey CD, Zhong H, Sobczyk A, van Aelst L, Svoboda K (2006) Supersensitive Ras activation in dendrites and spines revealed by twophoton fluorescence lifetime imaging. Nat Neurosci 9:283-291.

Yuste R, Peinado A, Katz LC (1992) Neuronal domains in developing neocortex. Science 257:665-669.

Zariwala HA, Madisen L, Ahrens KF, Bernard A, Lein ES, Jones AR, Zeng H (2011) Visual tuning properties of genetically identified layer 2/3 neuronal types in the primary visual cortex of cre-transgenic mice. Front Syst Neurosci 4:162.

Zheng J, Lee S, Zhou ZJ (2006) A transient network of intrinsically bursting starburst cells underlies the generation of retinal waves. Nat Neurosci 9:363-371.

Zhou ZJ (1998) Direct participation of starburst amacrine cells in spontaneous rhythmic activities in the developing mammalian retina. J Neurosci 18:4155-4165. 